\title{
Assessment of Vulnerable Buildings Due to Earthquake Loading Using Rapid Visual Screening Smartphone Application
}

\author{
Endah Wahyuni ${ }^{\#}$, Data Iranata ${ }^{\#}$, Budi Suswanto ${ }^{\text {, Cahyono B. Nurcahyo", Wahyuniarsih Sutrisno }}{ }^{\#}$ \\ \# Department of Civil Engineering Institut Teknologi Sepuluh Nopember, ITS Campus Surabaya 60111 Indonesia \\ E-mail: endah@ce.its.ac.id,iranata80@gmail.com,budisuswanto1973@gmail.com,cbintangn@yahoo.com,niar1206@gmail.com
}

\begin{abstract}
Examination of vulnerability level of buildings to earthquakes is divided into two types, the quick checks (Rapid Visual Screening, RVS) and a thorough examination. On thorough examination, it involves specialists of the field of building structures and other related fields, takes longer and is also cost much more expensive. While a quick check, it does not involve many specialists in a particular area, does not require a long time and are relatively inexpensive. This study builds an assessment of the vulnerability of buildings quickly adapted from FEMA 154 to the conditions and rules that applied in Indonesia using a smartphone application. A Global Positioning System (GPS) technology is used to mark the location of the data of the examination. The smartphone application called RViSITS is used to simplify and speed up the examination process and sent via the internet, and the server as a gathering and processing data. Furthermore, from these data do building vulnerability mapping and disaster-affected areas, which can then be accessed by the public, government and private sectors as well as database information. In this research, the RViSITS application process is to apply the application to do a quick check on the buildings in Surabaya, so that later the database and mapping vulnerability condition of buildings owned by government institutions in Surabaya against earthquake loadings can be made. While in general, this application can be used any places, so that the database and mapping the vulnerability of buildings can be held any area in Indonesia.
\end{abstract}

Keywords - rapid visual screening; FEMA 154; smartphone; vulnerability of buildings; earthquake; assessment.

\section{INTRODUCTION}

Earthquake is one of the disasters, which has caused much damage to the society, and it has been a threat to people for years [1]-[5]. There are numbers of lost, deaths and injuries as a result of an earthquake as shown in Fig. 1. The losses due to an earthquake event is directly related to the vulnerability of buildings and the awareness to provide first aid for people after the earthquake occur [6]. In many places, especially in Indonesia, many buildings were not designed according to the latest building and seismic code. In addition, there are no data related to the vulnerability of each building to the earthquake which resulting damage to numbers of buildings during the earthquake. In fact, the seismic safety of the building is crucial to reduce losses due to the earthquake.

Several researchers have been conducting research related to the seismic evaluation of the building. The research combined several methods such as visual examination, probability analysis, and also numerical modeling [1], [2], [5], [7], [8]. Among the several methods, which have been introduced to assess the seismic vulnerability of building, the thorough examination method is the most popular technique. On thorough examination, it involves specialists in the field of building structures and other related fields takes longer and is also cost much more expensive. Therefore, Federal Emergency Management Agency (FEMA) proposed a method called Rapid Visual Screening (RVS) to resolve the problem [8], [9], which is FEMA 154. The RVS is a procedure to evaluate the safety of buildings quickly and inexpensively subjected to earthquake loading. This method can also be done with minimum access to the buildings as it can be done by circling the building from the outside, and determining whether the structures require more detailed to be examined.

The RVS technique has been used by several researchers to evaluate the seismic vulnerability of building [6], [10]. On the research, the RVS techniques were applied to different type of the building such as hospital and different type of brick masonry building. Even though the RVS method can perform relatively quickly, several steps of this approach still require much time to be implemented, for example, the recapitulation step for the survey result. It needs much time to compile all data from the surveyors into a digital data. Furthermore, with the assumption that there is no mistake in the data verification step, the step of determining the area, which affected by the disaster, is still susceptible to an error. This step is critical for vulnerability mapping of buildings, which are exposed by earthquakes. Also, if there is a change 
in some data, the surveyor cannot use the old form and must change it with the new one, which is not effective and efficient.

Therefore, the primary purpose of this research is to establish the rapid visual screening smartphone application, which can be used to identify and evaluate the seismic vulnerability of buildings due to the earthquake. The application was developed under an Android platform. All step of rapid visual screening used in this application was adopted from the FEMA 154 code. This application was connected to Global Positioning System (GPS), and all data will be stored in the online database. By using this integrated system, this application is expected will simplify the mapping procedure for the vulnerability of building in Indonesia due to the earthquake.

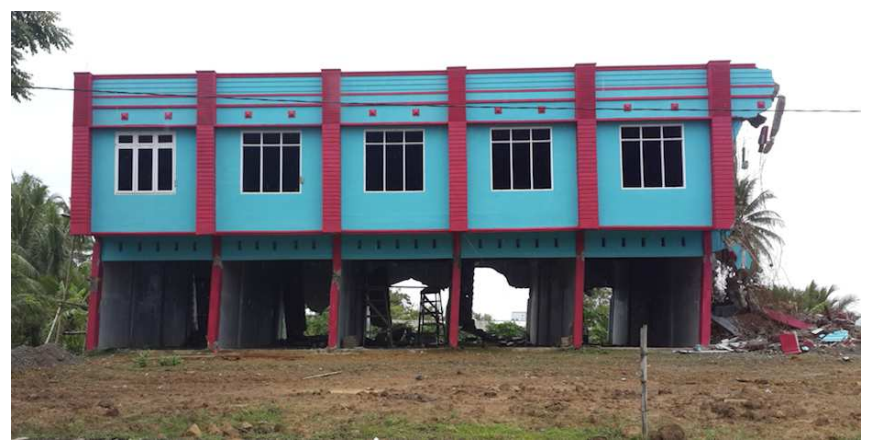

Fig. 1. Collapse of the Building in Aceh due to Earthquake

\section{MATERIAL AND METHOD}

\section{A. Assessment using RVS}

RVS is one of the methods to evaluate which is used to assess the vulnerability of buildings to earthquake hazards. The RVS procedure can be utilized for identifying potentially hazardous structures on a building within a relatively short duration and without the high costs. It also does not require detailed seismic analyses of individual buildings. This method involves a sidewalk survey, which is used to collect data and information related to the main parameters, which can affect the seismic vulnerability of the buildings.

The FEMA has been developed a guideline for the seismic hazard assessment and rehabilitation of buildings called FEMA 310. The FEMA 310 provides a three-tiered process for the seismic evaluation of existing buildings in any seismic area. According to FEMA310, before using the three methodologies provided in the guidelines, a RVS of the building should be carried out to decide if an assessment is necessary. The RVS technique is provided by FEMA 154.

The RVS procedure in FEMA 154 uses a system with numbering values. The system requires the user to recognize the main structural load-bearing resisting system and to modify the expected performance of the building subjected to earthquake loadings. The results are recorded on a Data Collection Form as shown in Fig. 2. This data is based on the earthquake region where the building will be surveyed or assessed. There are three types of Data Collection Forms, and they are divided based on the seismicity data. To identify the correct form to be used, for each seismic area, a range of spectral acceleration responses is provided. The method assigns a primary structural score based on the structural typology and uses score modifiers to consider the effect of the story-number, type of soil, vertical and horizontal irregularities, and pre- or post- benchmark-codes of the existing buildings.

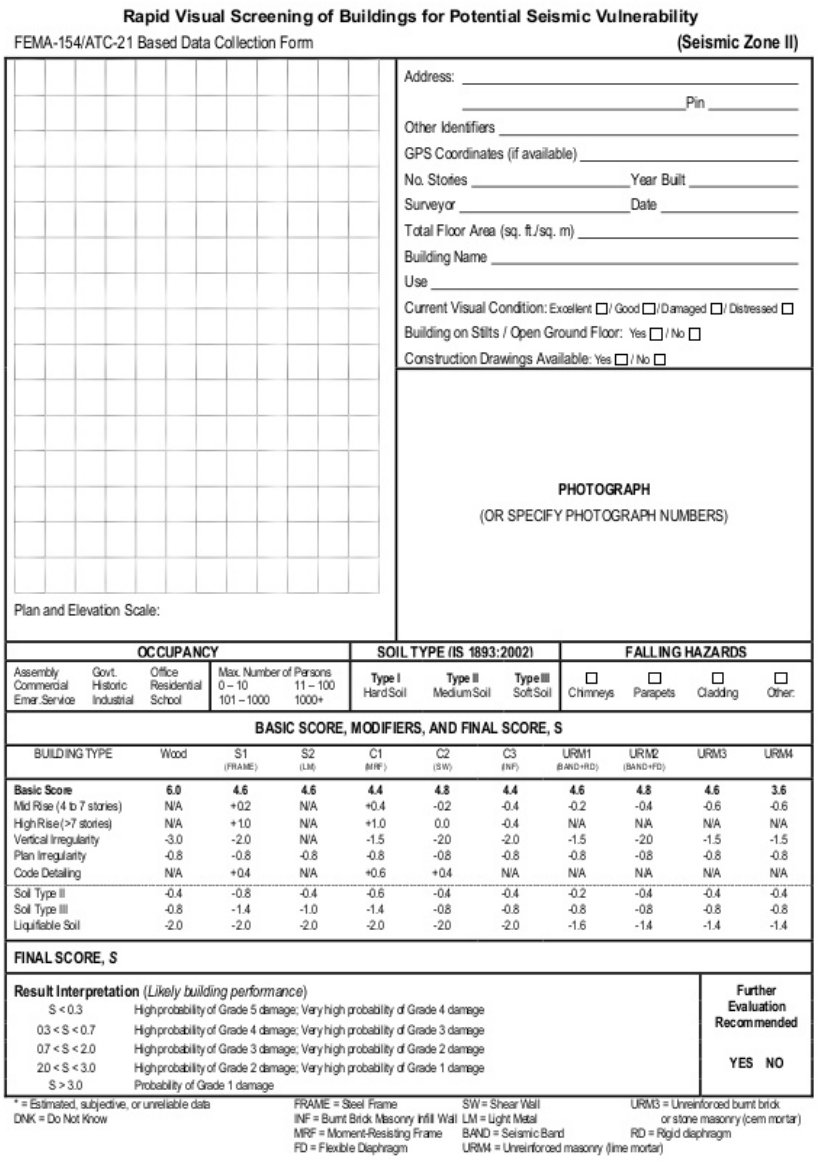

Fig. 2. Rapid Visual Screening Form in FEMA 154

\section{B. Research Methodology}

The main purpose of this study is to establish the rapid visual screening smartphone application, which can be used to identifying potentially hazardous buildings due to an earthquake. The research is divided into three main activities. The illustration of research methodology can be seen in Fig. 3. The first step of this research was focused on collecting data and performed a preliminary study related to the assessment of the potentially earthquake-affected building. The preliminary study including sorting references and regulations and also performed score factor analysis on RVS form based on FEMA 154. The second step is developing the rapid visual screening smartphone application RViSITS. This application is developed with Android platform and based on the FEMA 154. At the end of this research, a series of field-testing was performed to verify the RViSITS application. RViSITS application examined four buildings and verified by a numerical analysis using SAP 2000 to find out the performance of the four buildings based on Indonesian seismic design regulation of SNI 1726:2012. The result of each analysis was compared to check the accuracy of the RViSTS performance. 


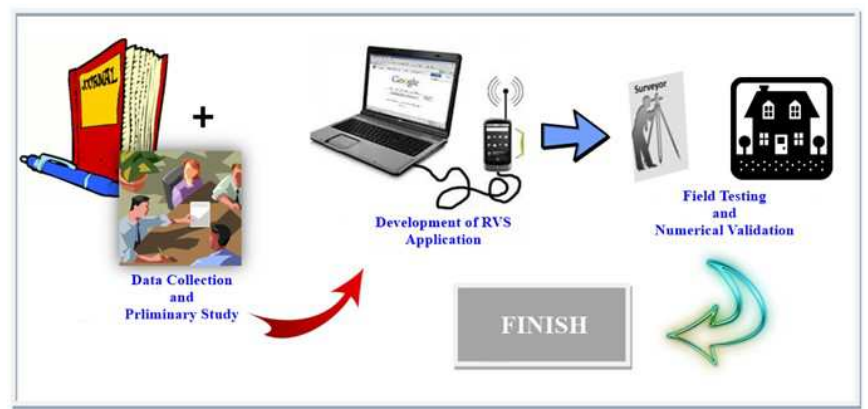

Fig 3. Illustration of Research Methodology

\section{RESULTS AND DISCUSSION}

\section{A. Score Factor}

The scoring factors in FEMA 154 for each building structures were analyzed to find out what the most significant factor that they could affect the RVS score. There are three kinds of the score, which are necessary, modifier and final scores. The Basic (B) score, Modifiers (M) score, and Final Structural (S) score are related to the probability of building collapse. The preliminary analysis of the proposed building can be useful as a reference during the field survey.

Based on the RVS analysis, there are 15 structural building types related to the B score, i.e., wood frame, steel moment-resisting and braced frames, concrete in-situ and precast frames, and reinforced masonry frames. The $M$ scores are calculated based on to the number of stories, the plan irregularities both in vertical and horizontal, pre- and post-benchmark scores, and types of soil, i.e., soft rock soil (type C); Stiff soil (type D) and Soft soil (type E). The final score $(\mathrm{S})$ corresponds to the seismic performance. The score typically ranges from 0 to 7 , with higher $S$ scores means the better performance of the structure subjected to earthquake loading. Based on present seismic design criteria, the cut off for the $S$ score is suggested limited to the value of 2 . The building with $\mathrm{S}$ scores of 2 or less must be examined by a professional designer who has been experienced in seismic design.

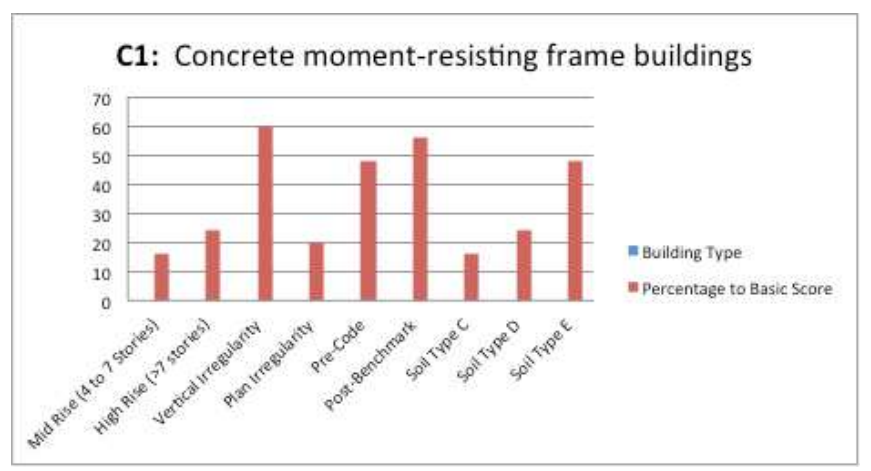

Fig 4. Comparison of Modifier to Basic scores of $\mathrm{C} 1$

The comparison between the component of the M scores can be analyzed to see which component of the scores are more influence comparing with others. Fig. 4 is an example of the structural type of concrete moment resisting frame buildings ( $\mathrm{C} 1)$. As shown in Fig. 4, the components of $\mathrm{M}$ scores that must be noticed are the vertical irregularity and post-benchmark code which the both scores has a high score. It means the component will have an influence more on the final score (S Score).

There is a difference between Indonesian code and FEMA 154 for the study cases in Surabaya and Sidoarjo, East Java, Indonesia, where according to Indonesian codes the location is in a moderate earthquake zone, but the FEMA 154 states that they are in high seismic zone. Based on SNI 1726: 2012, the acceleration of the period of 0.2 second of the Surabaya City is $0.663 \mathrm{~g}$, and the acceleration of the 1 -second period is $0.248 \mathrm{~g}$. For the Sidoarjo City, the acceleration of the earthquake response is $0.68 \mathrm{~g}$ for the period of 0.2 seconds, and for the period of 1 second is $0.266 \mathrm{~g}$. It means that the Surabaya and Sidoarjo cities are in the Moderate Seismicity according to the earthquake zone based on SNI 1726:2012, but it is in High Seismicity zone according to FEMA 154. Thus this paper used the RVS High Seismicity zone.

\section{B. Development of RViSITS Application}

Mobile-based Android has been very popular these days and the over the time the price is getting cheaper and it also offers various options to the customer. Due to its userfriendly system, an Android-based application is prevalent, and for that reason, this research purposed to develop an android application based on the FEMA 154 form to assess the vulnerability of buildings due to the earthquake.
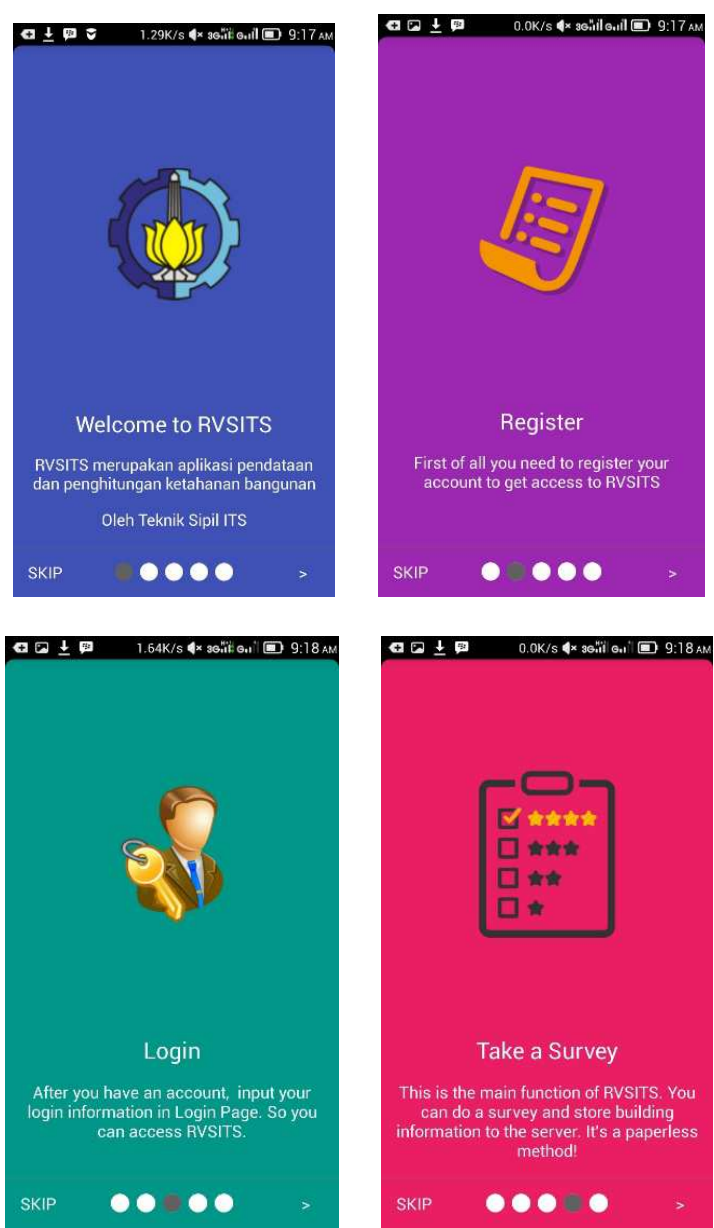

Fig. 5. Welcome Screen of RViSITS App 
The Android-based application program is expected to be used by the varied community. Android application program was made to facilitate the field assessment survey, and afterward, the data can be immediately sent to the website as a database. The data sent to the server will also contain coordinates of the building location. This data later can be used as data mapping building against the potential of the earthquake hazard.

This android program is named RViSITS, and this application is an update of previous versions. The new version of the application has been more users friendly so that it can be used more efficiently. After installing the application on the android phone, it will appear the home page as can be seen in Fig. 5. By sliding the screen on the home page will be presented steps of use of this application.

The survey started by fulfilling the building data, which include building name, address, built date, total floor area, and picture. The location of the building will be integrated with a global positioning system (GPS). After complete this step, the survey continued with fill the form one by one. Fig. 6 shows step by step completing the survey with RViSITS app. At the last stage, the primary score must be filled on, and the score will be appearing on the screen. The surveyor also can include their comment at the last screen.
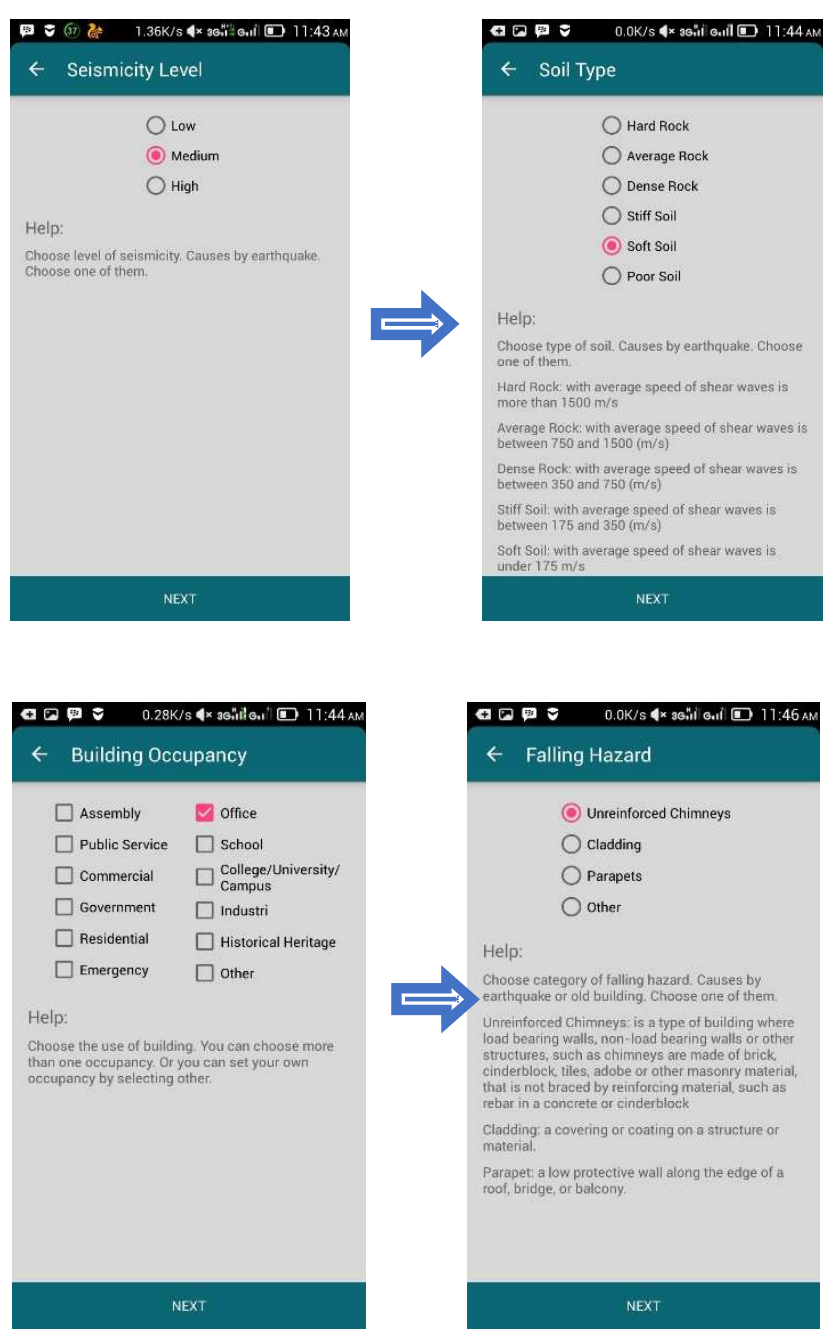
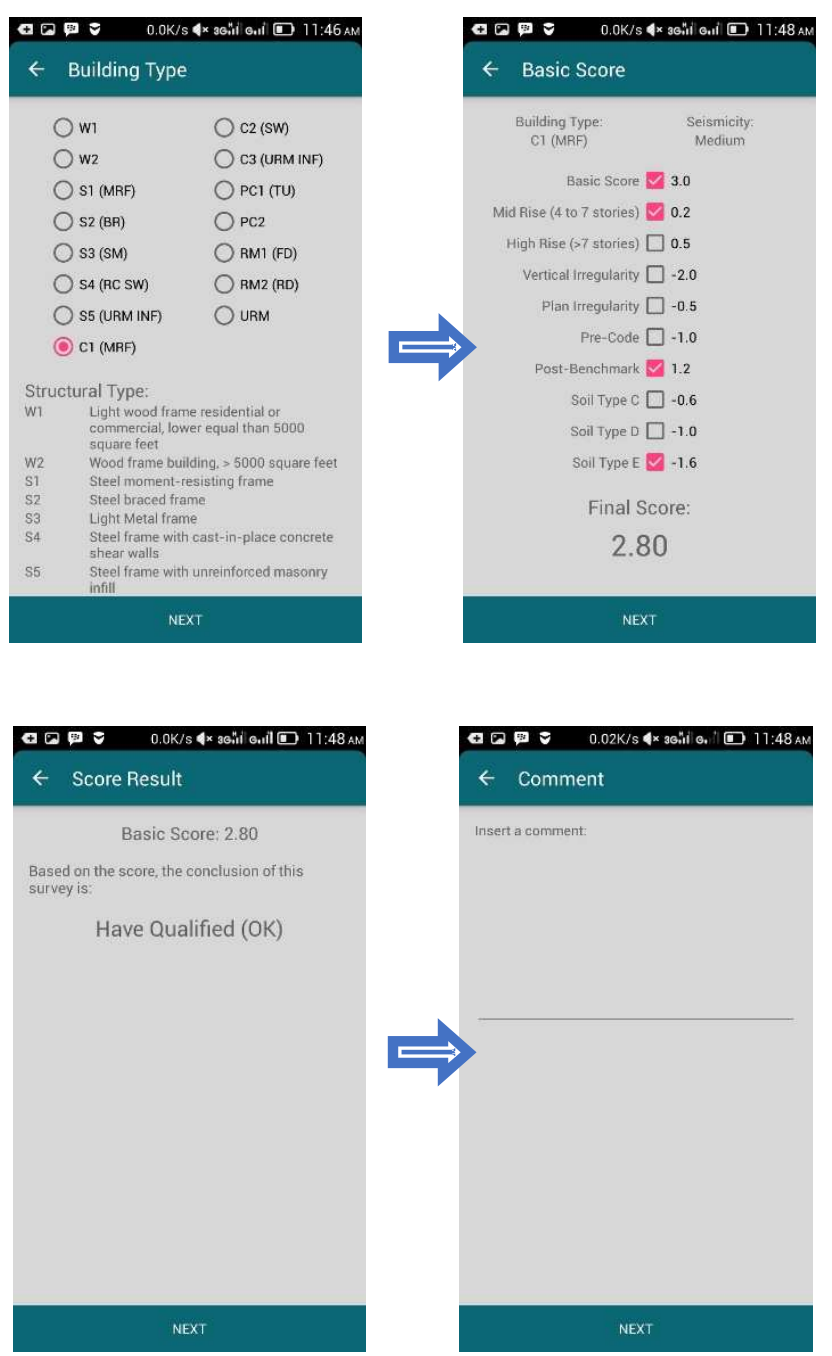

Fig. 6. Step by Step Form Filling on RViSITS App.

\section{Field Survey and Numerical Analysis}

The field survey was performed to verify the RViSITS application. The survey was taken at four buildings in Surabaya area, i.e., buildings of Badan Penanggulangan Bencana Daerah Jawa Timur (BPBD JATIM), Dinas Komunikasi and Informatika Jawa Timur (KOMINFO JATIM), PT. Alstom Power ESI and P. Bank Surabaya. Besides to conduct an assessment using the RViSITS application, the survey was also performed to obtain data, which used for numerical analysis. The results from numerical analysis were compared to the RVS survey results using RViSITS application.

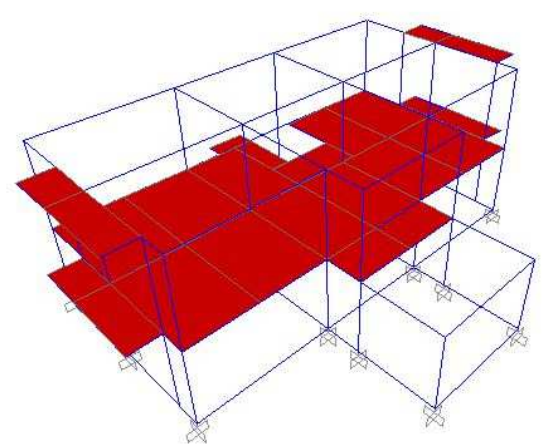

(a) BPBD Building JATIM 


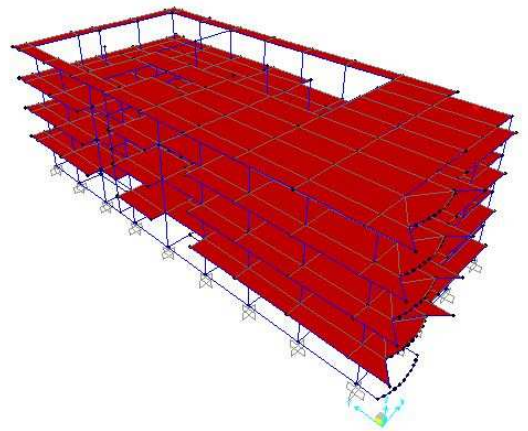

(b) KOMINFO Building JATIM

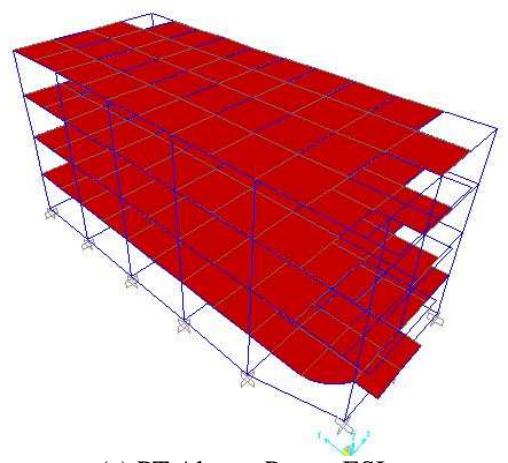

(c) PT.Alstom Power ESI

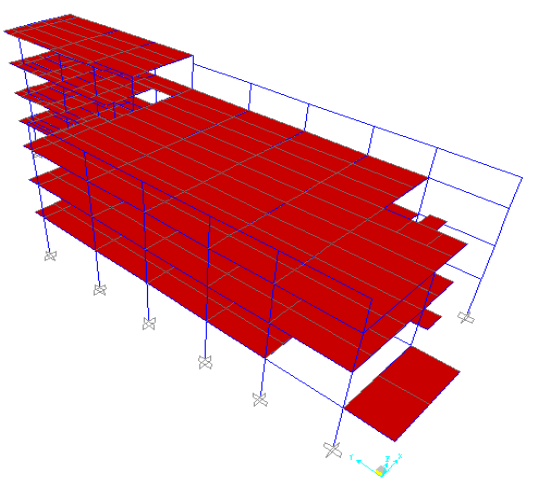

(d) P. Bank Surabaya

Fig. 7. Numerical Modelling Using SAP 2000 for 4 case studies

The numerical analyses of the four buildings were performed by using SAP 2000. This program was used to analyze whether the structure meets the requirements of Indonesian codes $[11,12]$. The Indonesian codes used in this research are SNI 1726:2012, which is a standard of earthquake resistance planning procedures for building and non-building structures, and SNI 2847:2013, which is about concrete structural requirements for buildings. Fig. 7 presents the model of four buildings, which used SAP2000.

The structural base shear controls of the four building are found that the dynamic base shears are more than $85 \%$ of the static base shears. It means that the performances of the buildings in the base shear requirements are fulfilled. The mass participation controls, which are more than $90 \%$ of the four buildings, are also fulfilled.

The controls of structural periods of the four buildings are fulfilled except for the P. Bank building, which is more than the permissible period. The drift of the four buildings are analyzed in $\mathrm{x}$ - and $\mathrm{y}$-directions. The results show that the drifts of the both directions are fulfilled for the buildings except the P. Bank building in the y-direction. The reason, why the P. Bank building does not meet the requirements of the central period control and drift in the y-direction, is because the building was built in 1985 and in that year, there is no requirement for seismic control, including the fundamental period and drift controls. The seismic building regulation was still using a static earthquake analysis, while the provisions on natural period control and others were used for the dynamic earthquake load modeling arranged in the year of 2002 and above.

Before conducting a survey, a pre-field data collection should be prepared. The data of the existing building needs to be reviewed and to identify the databases of the document information of buildings, which are the built time, address, storey number, function and identifying types of soil for the survey area. For this research, a numerical analysis also has been done to find out the performance of the building as mention in the above section.

After collecting pre-field data, a survey filed can be conducted on the buildings. The process of individual buildings is as follows [9]: 1. Updating and checking the information of the building data from pre-field data collection, and taking photos of the building; 2. Walking around the building and take photos of the buildings to see the condition of the buildings; 3. Determine occupancy, i.e. the building function and number of occupants; 4 . Determine the soil type of ground data using the available soil investigation data of the building; 5. Identify non-structural elements of the building due to earthquake loading; 6 . If possible, entering the surveyed building to identify a lateralseismic load-bearing system and choose the B Score in the RViSITS application; 7. Identify and click on the attributes of the appropriate seismic performance attribute of the $\mathrm{M}$ Score (e.g., built date, storey number and type of soil) in the input data of RViSITS program; 8. The Final Score, $\mathrm{S}$ can be determined by adjusting the B Score with the M Score Modifiers as mention in the Step 7, which appears automatically in the RViSITS application, and input a statement if the detailed evaluation of the building is required.

Table 1 shows the comparison between the results of the FEMA 154 using RViSITS application and the requirements of SNI 1726:2012 [11, 13]. It can be summarised that the four buildings are secure subjected to earthquake loading, both using the RVS assessment and the Indonesian standard, except the P. Bank Building. It is because the P. Bank building was built in 1985, which is still used the old earthquake regulation as mention in the previous section.

TABLE I

COMPARISON OF RVS AND NUMERICAL ANALYSIS BASED ON SNI 1726:2012

\begin{tabular}{|c|c|c|c|}
\hline Building name & $\begin{array}{c}\text { FEMA 154 } \\
\text { SCORE }\end{array}$ & $\begin{array}{c}\text { FEMA } \\
\text { NOTE }\end{array}$ & $\begin{array}{c}\text { SNI } \\
\mathbf{1 7 2 6}\end{array}$ \\
\hline BPBD JATIM Building & $2.7>2$ & Ok & Ok \\
\hline $\begin{array}{c}\text { KOMINFO JATIM } \\
\text { Building }\end{array}$ & $3.1>2$ & Ok & Ok \\
\hline $\begin{array}{c}\text { PT.Alstom Power ESI } \\
\text { Building }\end{array}$ & $3.7>2$ & Ok & Ok \\
\hline P Bank Building Surabaya & $1.9<2$ & Not Ok & Not Ok \\
\hline
\end{tabular}




\section{CONCLUSIONS}

The conclusion of this study can be stated as follows: The buildings used as a case study, which are the BPBD JATIM Office, KOMINFO JATIM and PT. Alstom Power ESI buildings, are declared secure against earthquake either by using RViSITS application or SNI 1726:2012, except for P. Bank Surabaya, where this building is declared unsafe either by RVS Method or by SNI 1726:2012 where this building is not fulfill all requirements, i.e. drift control in the y-direction which arranged in SNI 1726:2012, but it is safe in the $\mathrm{x}$ direction. The buildings are located in Surabaya and Sidoarjo Cities, where both cities are located in Indonesia's medium earthquake zone, thus based on Indonesian standard it should be used the moderate seismicity form, but according to FEMA 154, the buildings located in high seismic zone. The surveyor should be careful to use this RVS method. The RViSITS application can be used to assess the building subjected to earthquake loading. This result from the application is verified by the numerical analysis, and shows the same outcome.

\section{ACKNOWLEDGEMENT}

The research funding described in this paper was provided by Institut Teknologi Sepuluh Nopember Leading Research Grant 2017.

\section{REFERENCES}

[1] S. Sultana, U. Rahman, and U. Saika, "Earthquake, Cause Susceptibility and Risk Mitigation in Bangladesh," ARPN Journal of Earth Science, Vol. 2, No. 2, Pp. 70-80, 2013.

[2] U. Hancilar, E. Çakt, M. Erdik, G. E. Franco, and G. Deodatis, "Earthquake Vulnerability of School Buildings: Probabilistic Structural Fragility Analyses,"Soil Dynamics and Earthquake Engineering, Vol. 67, Pp. 169-178, 2014.
[3] E. Wahyuni, T. Ji, "Relationship between static stiffness and modal stiffness of structures", IPTEK the Journal for Technology and Science, Vol. 21 (2), 55-59, 2010.

[4] M. Roghaei And A. Zabihollah, "An Efficient And Reliable Structural Health Monitoring System For Buildings After Earthquake," Procedia - Soc. Behav. Sci., Vol. 9, Pp. 309-316, 2014.

[5] S. T. Karapetrou, S. D. Fotopoulou, and K. D. Pitilakis, "Seismic Vulnerability of RC Buildings under the Effect of Aging," Procedia Environ. Sci., Vol. 38, Pp. 461-468, 2017.

[6] D. Perrone, M. Antonietta, M. Pecce, and F. Rossi, "Rapid Visual Screening For Seismic Evaluation of RC Hospital Buildings," Structures, Vol. 3, Pp. 57-70, 2015.

[7] A. Formisano And A. Marzo, "Simplified And Refined Methods For Seismic Vulnerability Assessment And Retrofitting Of An Italian Cultural Heritage Masonry Building," Comput. Struct., Vol 180, Pp. 13-26, 2017.

[8] Sutrisno, W., Hartana, I.K., Suprobo, P., Wahyuni, E., Iranata, D., "Cracking process of reinforced concrete induced by non-uniform reinforcement corrosion". Jurnal Teknologi, Vol. 79 (3), pp.1-6, 2017.

[9] ATC, Rapid Visual Screening of Buildings for Potential Seismic Hazards: A Handbook (2nd Edition), Prepared By the Applied Technology Council for the Federal Emergency Management Agency, Fema 154 Report. Washington D.C., 2002.

[10] C. Adam, "A Rapid-Visual-Screening Methodology for the Seismic Vulnerability Assessment of Historic Brick-Masonry Buildings in Vienna," 15 Wcee Conf. Lisboa, Vol. 154, No. 2002, 2011.

[11] E. Wahyuni, Tethool, Y. "Effect of Vierendeel Panel Width and Vertical Truss Spacing Ratio in Staggered Truss Framing System". International Journal of Civil Engineering. 2015; 13(2): 213-221.

[12] E. Wahyuni, Komara, I., Suswanto, B, "Effect of Triangle Cables Configuration on The Behavior of Reinforced Concrete Submerged Floating Tunnel under Hydrodynamic Load", IABSE Symposium 2017, Vancouver, Canada, 21-23 September, 2017.

[13] E. Wahyuni, "Vulnerability Assessment of Reinforced Concrete Building Subjected to Seismic Loads Using Pushover Analysis", Procedia Earth and Planetary Science, Vol. 14, Pp. 76-82, 2015.

[14] Dai,K., Wang, J., Li, B., Hong, H.P., "Use of residual drift for postearthquake damage assessment of RC Buildings", Engineering Structures, Vol. 147, Pp. 242-255, 2017. 